\title{
Geophysical phenomena during an ionospheric modification experiment at Tromsø, Norway
}

\author{
N. F. Blagoveshchenskaya ${ }^{1}$, V. A. Kornienko ${ }^{1}$, A. V. Petlenko ${ }^{1}$, A. Brekke ${ }^{2}$, M. T. Rietveld ${ }^{3}$ \\ ${ }^{1}$ Arctic and Antarctic Research Institute (AARI), 199397, St. Petersburg, Russia \\ ${ }^{2}$ Auroral Observatory, University of Tromsø, N-9037, Tromsø, and The University Courses of Svalbard, Svalbard, Norway \\ ${ }^{3}$ EISCAT, N-9027 Ramfjørdbotn, Norway
}

Received: 13 October 1997 / Revised: 11 May 1998 / Accepted: 26 May 1998

\begin{abstract}
We present an analysis of phenomena observed by HF distance-diagnostic tools located in St. Petersburg combined with multi-instrument observation at Tromsø in the HF modified ionosphere during a magnetospheric substorm. The observed phenomena that occurred during the Tromsø heating experiment in the nightside auroral $\mathrm{E}_{\mathrm{S}}$ region of the ionosphere depend on the phase of substorm. The heating excited smallscale field-aligned irregularities in the $\mathrm{E}$ region responsible for field-aligned scattering of diagnostic HF waves. The equipment used in the experiment was sensitive to electron density irregularities with wavelengths $12-15 \mathrm{~m}$ across the geomagnetic field lines. Analysis of the Doppler measurement data shows the appearance of quasiperiodic variations with a Doppler frequency shift, $f_{d}$ and periods about $100-120 \mathrm{~s}$ during the heating cycle coinciding in time with the first substorm activation and initiation of the upward field-aligned currents. A relationship between wave variations in $f_{d}$ and magnetic pulsations in the $Y$-component of the geomagnetic field at Tromsø was detected. The analysis of the magnetic field variations from the IMAGE magnetometer stations shows that ULF waves occurred, not only at Tromsø, but in the adjacent area bounded by geographical latitudes from $70.5^{\circ}$ to $68^{\circ}$ and longitudes from $16^{\circ}$ to $27^{\circ}$. It is suggested that the ULF observed can result from superposition of the natural and heater-induced ULF waves. During the substorm expansion a strong stimulated electromagnetic emission (SEE) at the third harmonic of the downshifted maximum frequency was found. It is believed that SEE is accompanied by excitation of the VLF waves penetrating into magnetosphere and stimulating the precipitation of the energetic electrons (10-40 keV) of about 1-min duration. This is due to a cyclotron resonant interaction of natural precipitating electrons $(1-10 \mathrm{keV})$ with heater-induced whistler waves in the magnetosphere. It is reasonable to
\end{abstract}

Correspondence to: N. F. Blagoveshchenskaya

E-mail: nataly@aari.nw.ru suppose that a new substorm activation, exactly above Tromsø, was closely connected with the heater-induced precipitation of energetic electrons.

Key words. Ionosphere (active experiments; ionosphere - magnetosphere interactions). Radio science (nonlinear phenomena).

\section{Introduction}

Between 1980-1997 a large number of ionospheric modification experiments have been performed using the HF heating facility located at Ramfjørdmoen near Tromsø, Norway (Rietveld et al., 1993; Stubbe, 1996). Many efforts have been made to study experimentally and theoretically the ionospheric modification produced by powerful HF radio waves. These studies were concerned with different topics such as large- and small-scale field-aligned ionospheric irregularities (Djuth et al., 1985; Noble et al., 1987), stimulated electromagnetic emissions (Thide et al., 1982; Stubbe et al., 1984; Leyser et al., 1989; Leyser et al., 1990; Stubbe and Kopka, 1990), HF wave anomalous absorption particularly for heater frequencies near harmonics of the electron gyrofrequency (Stocker et al., 1993; Robinson et al., 1996), and secondary electromagnetic waves at very, extremely and ultra low frequencies by amplitudemodulated heating (Rietveld et al., 1993; Stubbe, 1996).

It should be noted that in the heating experiments performed at Tromsø to date the plasma physics aspect has clearly dominated. The geophysical aspect has not been adequately explored. In this connection the study of Yeoman et al. (1997) should be noted. It shows that the combination of the latest ionospheric radars and the Tromsø HF heater provide a powerful new tool for active geophysical researches. 
Nonetheless, taking into account the distinctive behavior and features of the auroral ionosphere such as the ionospheric convection, field-aligned currents, intense electrojets, precipitating particles one would expect that the heating of this medium can lead to the generation of modification effects not encountered in dayside undisturbed ionosphere.

Here we report on the geophysical phenomena observed in the Tromsø heating experiment in the nightside auroral ionosphere during a magnetospheric substorm on 17 February 1996. We used HF longdistance diagnostic tools located near St. Petersburg combined with multi-instrument observations at Tromsø.

\section{Experimental techniques and observations}

The experiment was conducted at the Tromsø heating facility $\left(69.6^{\circ} \mathrm{N}, 19.2^{\circ} \mathrm{E}, L=6.2\right)$ from $20.00 \mathrm{UT}$ on 17 February, 1996 in the nightside auroral ionosphere. The main technical parameters of the Tromsø heater during the experiment were the following: heater frequency $f=4040 \mathrm{kHz}, \mathrm{O}$-mode polarization, effective radiated power ERP $=150 \mathrm{MW}$, transmission scheme 4 min on / 6 min off. The ionospheric modification was produced in the near field-aligned direction, as the antenna beam was tilted $6^{\circ}$ to the south with respect to the zenith. The magnetic field inclination angle at Tromsø is close to $78^{\circ}$.

To study phenomena initiated by the action of powerful HF radio waves in the nightside auroral ionosphere during substorm we used the distancediagnostic HF tools located in St. Petersburg at a distance about $1200 \mathrm{~km}$ from the Tromsø heater. Doppler measurements of HF diagnostic signals were carried out on the London - Tromsø - St. Petersburg path using fixed operational frequency of $12095 \mathrm{kHz}$. The diagnostic transmitter was located in London. The reception of HF diagnostic waves scattered of fieldaligned artificial irregularities produced by the Troms $\varnothing$ heater was made by Doppler spectrum method at St. Petersburg. Spectral processing was carried out by the use of the fast Fourier transform (FFT) method. The analysis bandwidth used was $33 \mathrm{~Hz}$, a specified number of 1024 FFT coefficients allowed a frequency resolution of $0.032 \mathrm{~Hz}$. The receiving antenna was directed toward Tromsø.

Doppler measurements were supplemented by data from the Tromsø dynasonde (Sedgemore et al., 1998 and references therein), IMAGE magnetometer network (Lühr, 1994) and airglow at Skibotn.

Figure 1 shows the general view of the experiment geometry (Fig. 1a) and locations of the IMAGE magnetometers (Fig. 1b).

Figure 2 presents the dynamic Doppler spectra (sonogram) of the HF diagnostic signals at $12095 \mathrm{kHz}$ on the London - Troms $\varnothing-$ St. Petersburg path in the course of the heating experiment on 17 February, 1996. The field-aligned scattered signals appear after the heater is turned on and disappear after it is turned off.
They are registered as additional tracks on the negative part of Doppler sonogram shifted by about $-2.5 \mathrm{~Hz}$ from that of the direct signal propagating from the transmitter to the receiver along a great-circle path and corresponding to the $0 \mathrm{~Hz}$ Doppler frequency. From Fig. 2 it is clear that scattered signals are observed during all heating cycles from 20.00 to 20.46 UT.

Analysis of the Tromsø dynasonde ionograms, as well as EISCAT UHF radar data, during the heating experiment on 17 February, 1996 shows the presence of sporadic Es - layer at altitudes between 100 and $130 \mathrm{~km}$ sometimes with 0 - and $X$-mode traces on the dynasonde ionograms and maximal observed frequencies from 4.1 to $4.5 \mathrm{MHz}$. We may conclude that the Es region of the auroral ionosphere was actually the region which was heated. The heating leads to the generation of intense
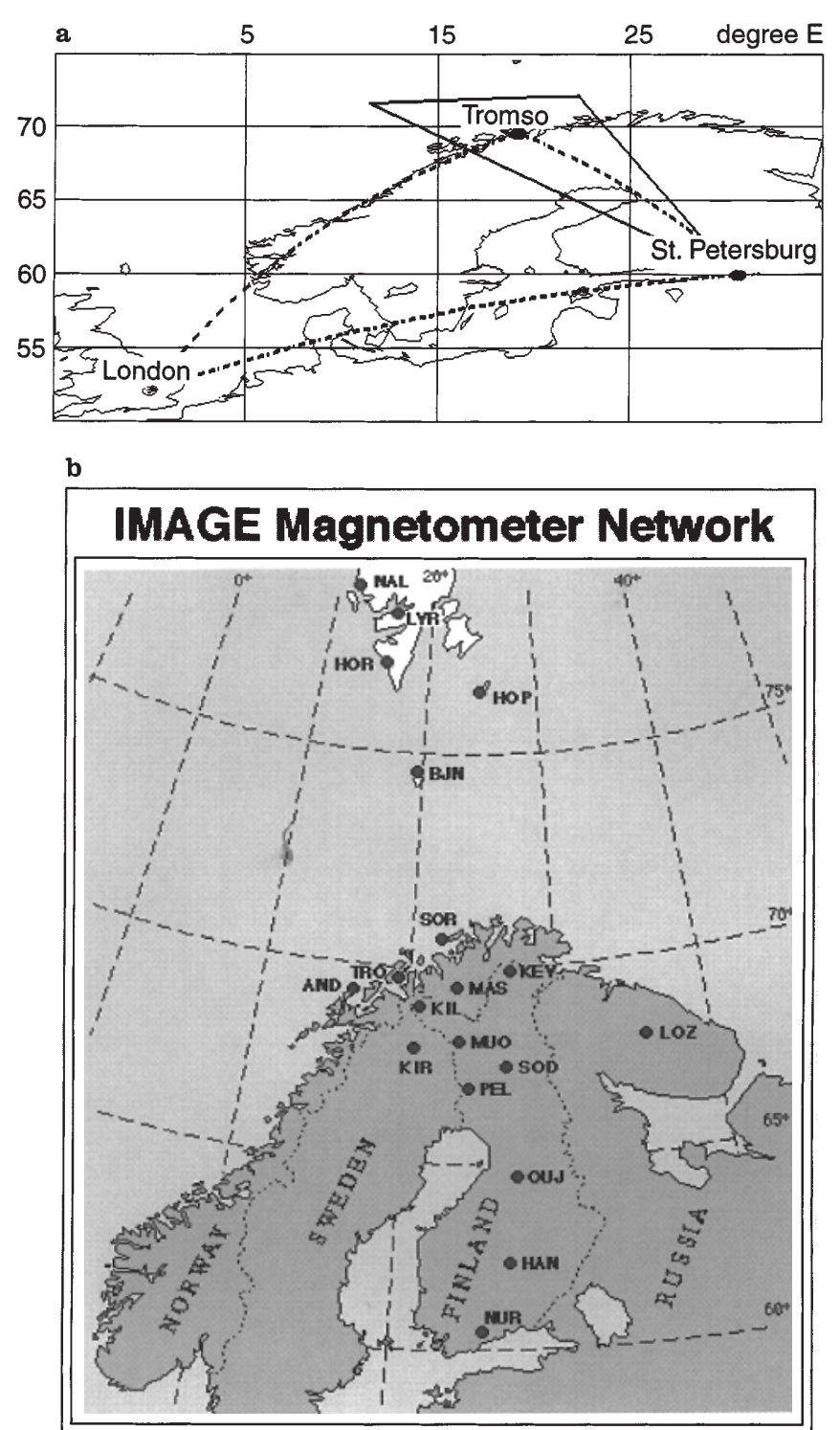

Fig. 1a, b. General view of the experiment geometry: a the radio path where the experimental observations of HF distance diagnostic signals scattered from artificial field-aligned irregularities were made; b locations of the IMAGE magnetometer stations used in this study 
artificial field-aligned irregularities (striations) in the Eregion of ionosphere responsible for field-aligned scattering of diagnostic HF signals on the LondonTromsø - St. Petersburg path.

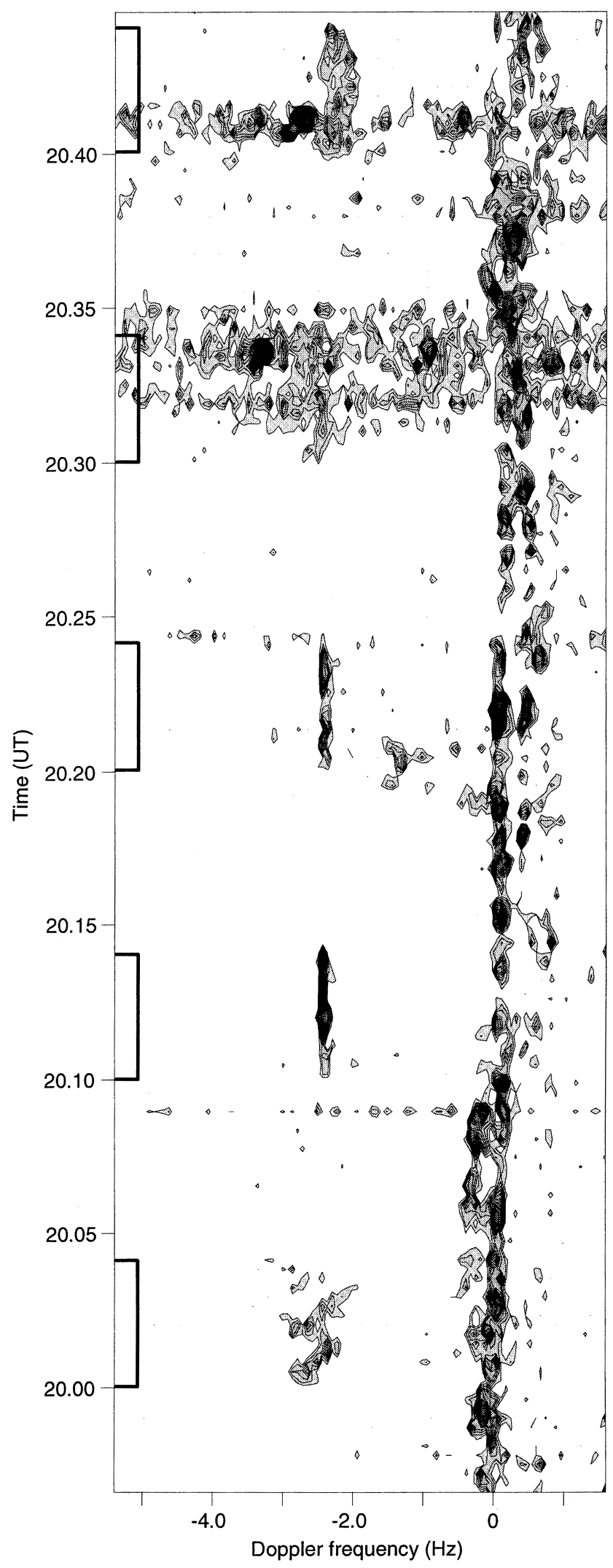

Figure $3 \mathrm{a}-\mathrm{c}$ shows the behavior of the magnetic field variations from IMAGE magnetic stations in the $X, Y$ and $Z$ components, respectively, on 17 February, 1996. The first substorm activation started at 20.00 UT with an increase of negative magnetic perturbations (Fig. 3a) accompanied by large positive bays in the Y-components (Fig. 3b). The IMAGE $X$ and $Z$ component features (Fig. 3a, c) show that a maximum westward electrojet appeared poleward from Tromsø between SOR and BJN magnetic stations. It is well known (Rostoker, 1996; Kamide and Baumjohan, 1993) that positive $Y$ component bays are detected near the western edge of the surge form produced by ionospheric Hall currents surrounding the region of the upward field-aligned currents (FACs) in the head of the surge. Note that FACs were turned on (or greatly intensified) at 20.00 UT and turned off at 20.33 UT as can be seen from the appearance and disappearance of the positive $Y$ component bays at the IMAGE magnetic stations (Fig. 3b).

The second substorm activation started at 20.33 UT as a large negative spike in the $X$ component and peaked at 20.34 UT from SOR to PEL magnetic stations (Fig. 3a). An inspection of peculiarities in the $X$ and $Z$ components at the IMAGE network (Fig. 3a, c) indicates that a new westward electrojet appeared exactly above Tromsø (maximum amplitude of negative spike in the $X$ component and $\delta Z=0$ ). Thereafter a much larger substorm occurred north of Troms $\varnothing$ at about 20.36 UT and peaked at 20.38 UT in the HOR magnetic station (Fig. 3a).

\section{Results and discussion}

An examination of dynamic Doppler spectra (Fig. 2) in course of the heating experiment on 17 February shows the following distinctive heating signatures during the auroral substorm.

Firstly, the occurrence of wave variations in the Doppler frequency shift, $f_{d}$, with periods about 100 $120 \mathrm{~s}$ was observed during the first heating cycle $(20.00$ 20.04 UT), coinciding in time with the onset of the substorm and initiation of the field-aligned currents.

Secondly, the occurrence of the electromagnetic emissions observed everywhere over the analyzed spectral bandwidth in the two heating cycles from 20.30 to 20.34 UT and 20.40-20.44 UT can be clearly seen.

Thirdly, the appearance of additional very intense short-lived tracks with a lifetime of order $60 \mathrm{~s}$ (apart from the main Doppler heating track on sonogram)

Fig. 2. The dynamic Doppler spectra (sonogram) of the HF distance diagnostic signals at operational frequency $12095 \mathrm{kHz}$ on the London - Tromsø - St. Petersburg path in the course of the heating experiment on 17 February, 1996. The direct signals propagating from the transmitter to the receiver along a great circle path correspond to the $0 \mathrm{~Hz}$ Doppler frequency. Additional tracks on the negative part of Doppler sonogram shifted by about $-2.5 \mathrm{~Hz}$ from that of the direct signals correspond to the field-aligned scattered signals. The intervals, when the Tromsø heating facility was turned on, are marked on the time axis 
17 February 1996, X component

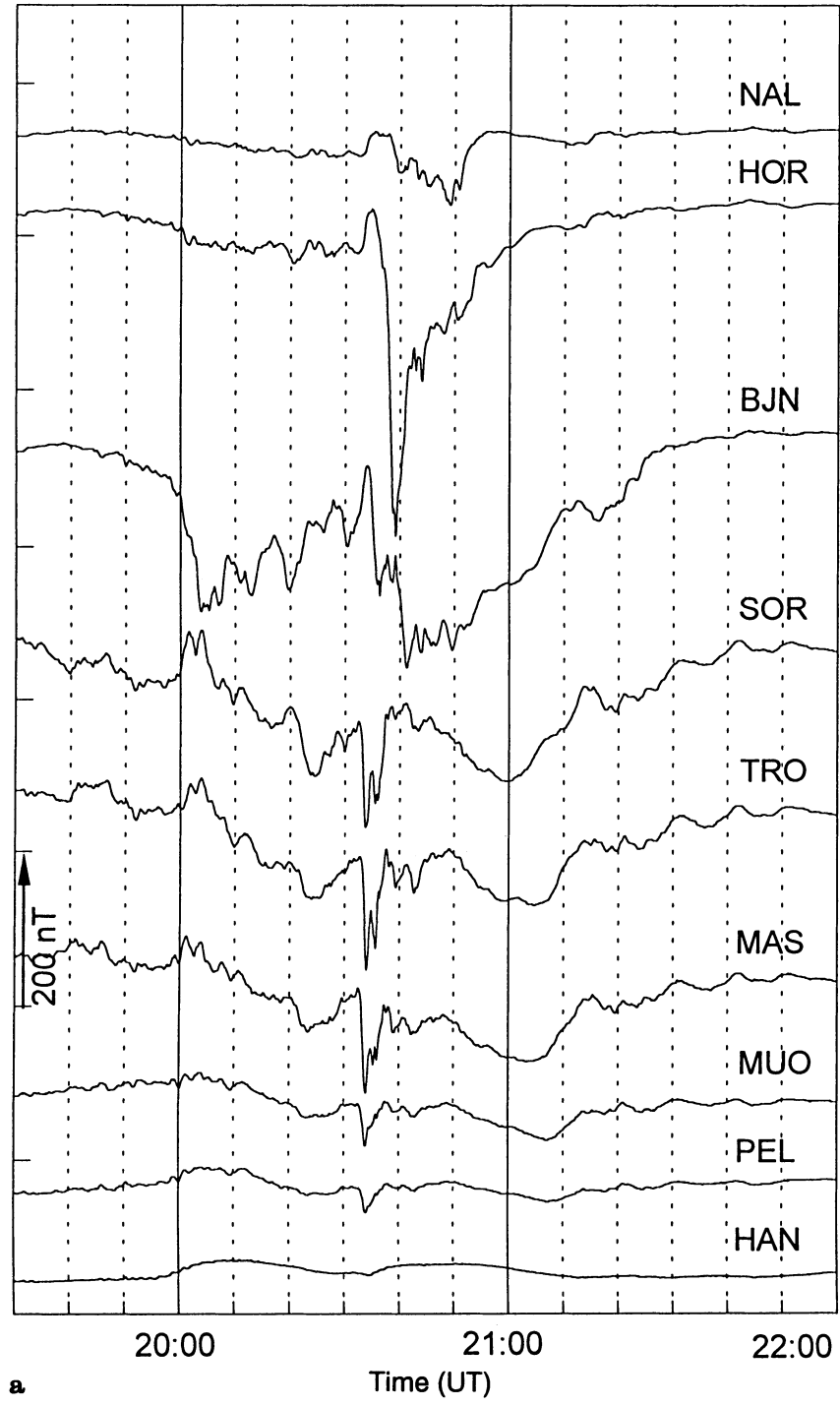

17 February 1996, Y component

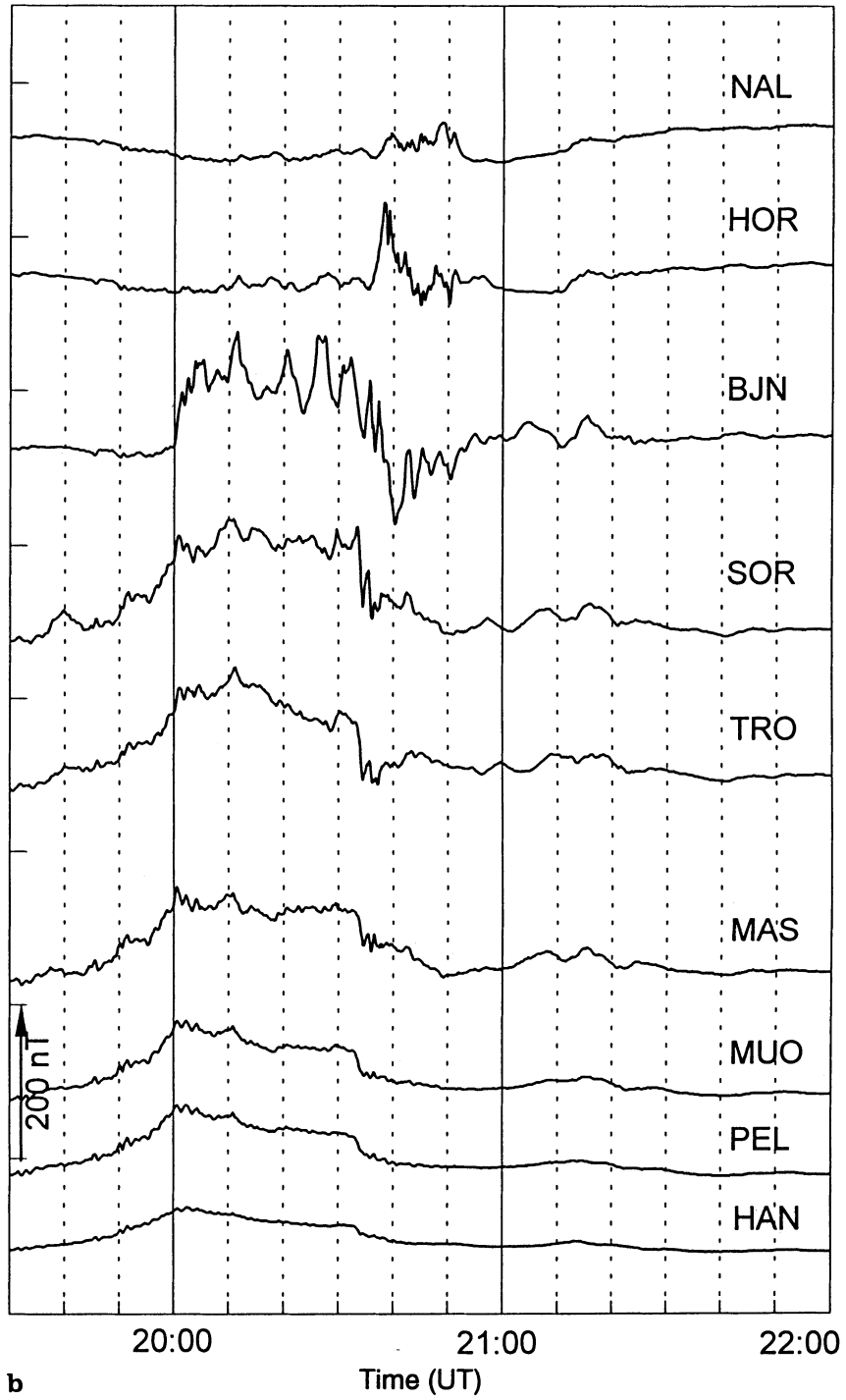

Fig. 3a-c. The behavior of the magnetic field variations from the IMAGE magnetometer stations: a X component; b Y component; c Z component

associated with the second substorm activation were detected in the same heating cycles where emissions were observed.

To study the geophysical phenomena during a heating experiment it is advantageous to use the variations of $X$ and $Y$ magnetic components from the quiet level. Figure 4 presents these variations obtained from IMAGE magnetometers located along the latitude from AND to KEV (Fig. 4a) as well as along the longitude from BJN to OUJ (Fig. 4b).

\subsection{Wave processes in the onset of the substorm}

The interesting peculiarity of the field-aligned scattered HF signals on London - Troms $\varnothing-$ St. Petersburg path is the appearance of the wave variations in Doppler shift, $f_{d}$, with periods about $100-120 \mathrm{~s}$ during the first heating cycle from 20.00 to 20.04 UT (Fig. 2). The amplitude of this ULF wave determined as the maximum fluctuation of $f_{d}$ during the heating cycle $\left(f_{\text {dmax }}-\right.$ $f_{d m i n}$ ) was about $0.8 \mathrm{~Hz}$. In the next heating cycles the variations of $f_{d}$ on the scattered signal are absent. The direct HF signal from London to St. Petersburg does not contain such variations during the whole interval analyzed.

It is of interest to compare the observed ionospheric small-scale wave process and magnetic variation data in Tromsø. There is evidence of the appearance of welldefined magnetic pulsations in the $Y$ component of the geomagnetic field (Fig. 4a) during the first heating cycle (20.00-20.04 UT). They have periods about 100-120 s and a large amplitude, of order 15-20 nT. Detailed comparison of the wave variations in Doppler shift, $f_{d}$, and magnetic (in the $Y$ component) pulsations at Tromsø during the first heating cycle is shown in Fig. 5 where close correlation between ionospheric and magnetic pulsations can be seen. 
It is appropriate to estimate the parameters of a ULF wave from Doppler measurement data. The relationship of ionospheric $\left(f_{d}\right)$ and magnetic field ( $Y$ component) fluctuations corresponds to correlation between variations in the meridional, north-south component of the electric field $\left(E_{x}\right)$ and zonal, east-west component of the magnetic field $\left(B_{y}\right)$ in the artificially modified ionospheric $\mathrm{E}_{\mathrm{s}}$ region produced by Tromsø heating facility during substorm onset. In this case on the assumption that electron drift in the $\mathrm{E}$ region is a pure $\mathbf{E} \times \mathrm{B}$ drift, from Doppler measurement data the vertical component of the Doppler velocity, the values of the vertical displacements of the artificially disturbed region of the ionosphere, and electric field of a ULF wave can be estimated.

The Doppler velocity $V_{d}$ is given by

$V_{d}=-\frac{f_{d \max } \cdot c}{2 f \cdot \cos \theta}$

\section{February 1996, Z component}

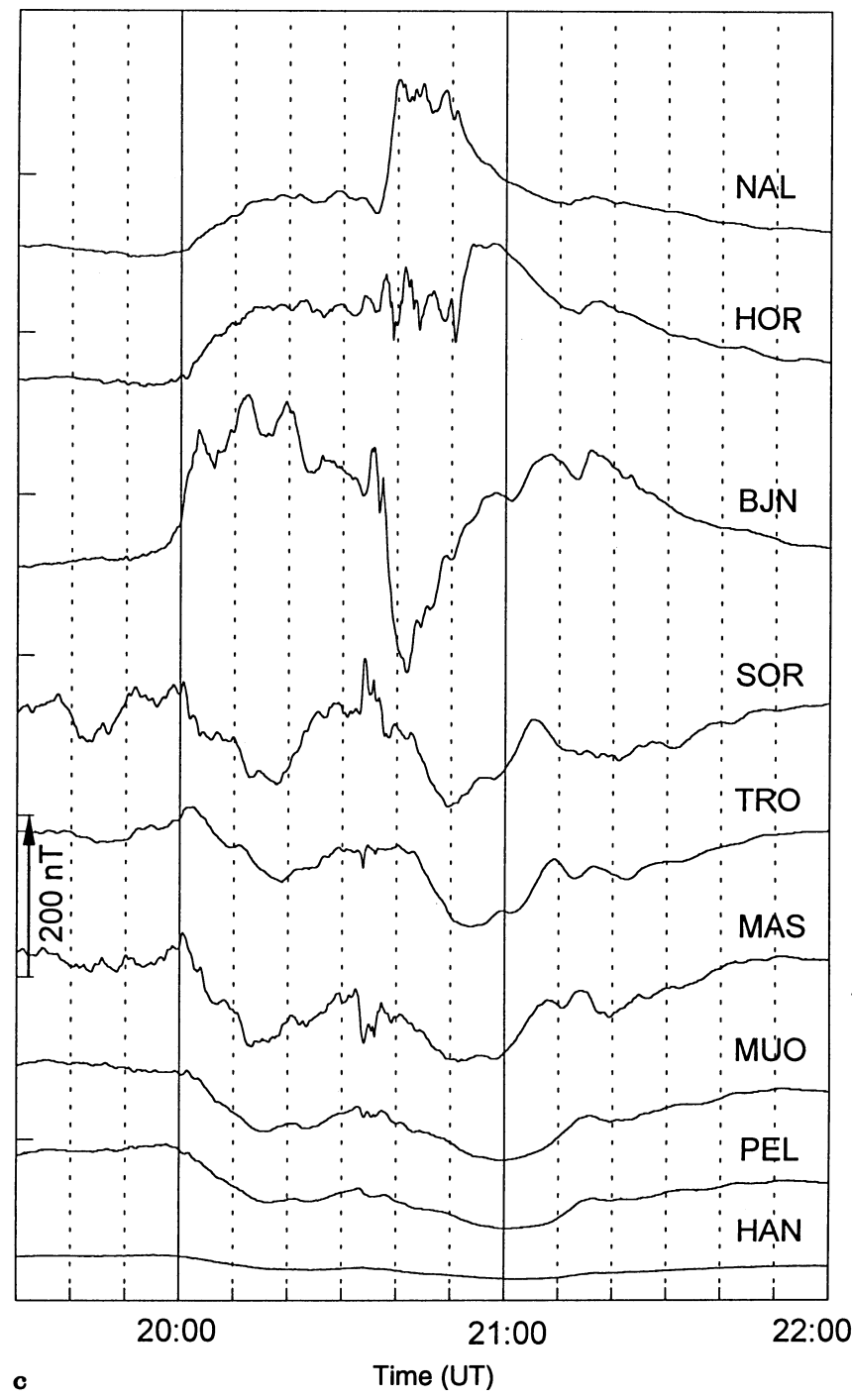

Fig. 3c. where $f_{\text {dmax }}$ is the maximum Doppler frequency shift, $f$ is the operational frequency, $\theta$ is the incidence angle of the diagnostic wave on the artificially disturbed region, and $c$ is the velocity of light.

Knowing the vertical component of the Doppler velocity $V_{d}$ and periods $T$ of oscillations of the Doppler frequency shift, one can estimate the values of the vertical displacement $M$ of the heated region of the ionosphere as

$M=T \cdot V_{d}$.

The electric field (north-south component) would be expressible as

$E_{x}=\frac{V_{d} \cdot B_{0}}{\cos I}$,

where $I$ is the angle of the magnetic declination and $B_{0}$ is the Earth's magnetic field.

Rough estimations using the values $f_{\text {dmax }}= \pm 0.4 \mathrm{~Hz}, \quad f=12095 \mathrm{kHz}, \quad \cos \theta=1$, $T=115 \mathrm{~s}, B_{0}=50 \mu \mathrm{T}, I=78^{\circ}$ give $V_{d}= \pm 5.2 \mathrm{~m} /$ $\mathrm{s}, M= \pm 600 \mathrm{~m}$ and $E_{x}= \pm 1.3 \mathrm{mV} / \mathrm{m}$.

It should be pointed out that the distinctive feature of the experiment is the use of continuous heating instead of amplitude-modulated heating of the ionosphere. This means that the duration of the heating cycle was significantly larger than the periods of the ionospheric (in $f_{d}$ ) and magnetic pulsations observed in the described experiment. Consequently, the origin of the ionospheric and magnetic pulsations could not be explained by modulation of the conductivity and, therefore, the current distribution flowing due to amplitude-modulated heating of the E-region. Thus, one can conclude that ionospheric and magnetic pulsations are possibly the result of modification of the specific nightside auroral ionosphere, by action of powerful HF radio waves on the Es region or they are natural pulsations during auroral substorm onset.

It would be expected that the substorm activation is accompanied by the generation of $\mathrm{Pi} 2$ magnetic pulsations of 40-150 s. In this case the ionospheric and magnetic pulsations observed during the first heating cycle could be signatures of natural pulsations. It should be noted that Yeoman et al. (1997) studied wave activity in the ULF band with CUTLASS radar and IMAGE magnetic stations, during the Tromsø experiment, of $\mathrm{F} 2$ region heating in the early evening hours, and attributed these to naturally occurring ULF waves.

To study this point in our heating experiment the magnetic field variations in $X$ and $Y$ components were considered from all IMAGE magnetometer stations during the onset of the substorm activation. The ULF waves in magnetic field measurements are shown in more detail in Fig. 6, which displays $X$ and $Y$ components from eight IMAGE magnetometers, covering geographical latitudes from $74.5^{\circ}-64.5^{\circ}$ and geographical longitudes from $16^{\circ}-27^{\circ}$, bandpass filtered between 120 and $80 \mathrm{~s}$. ULF waves can be seen both in the unfiltered (Fig. 4) and filtered (Fig. 6) magnetic data. An ULF wave is most pronounced in the first heating 

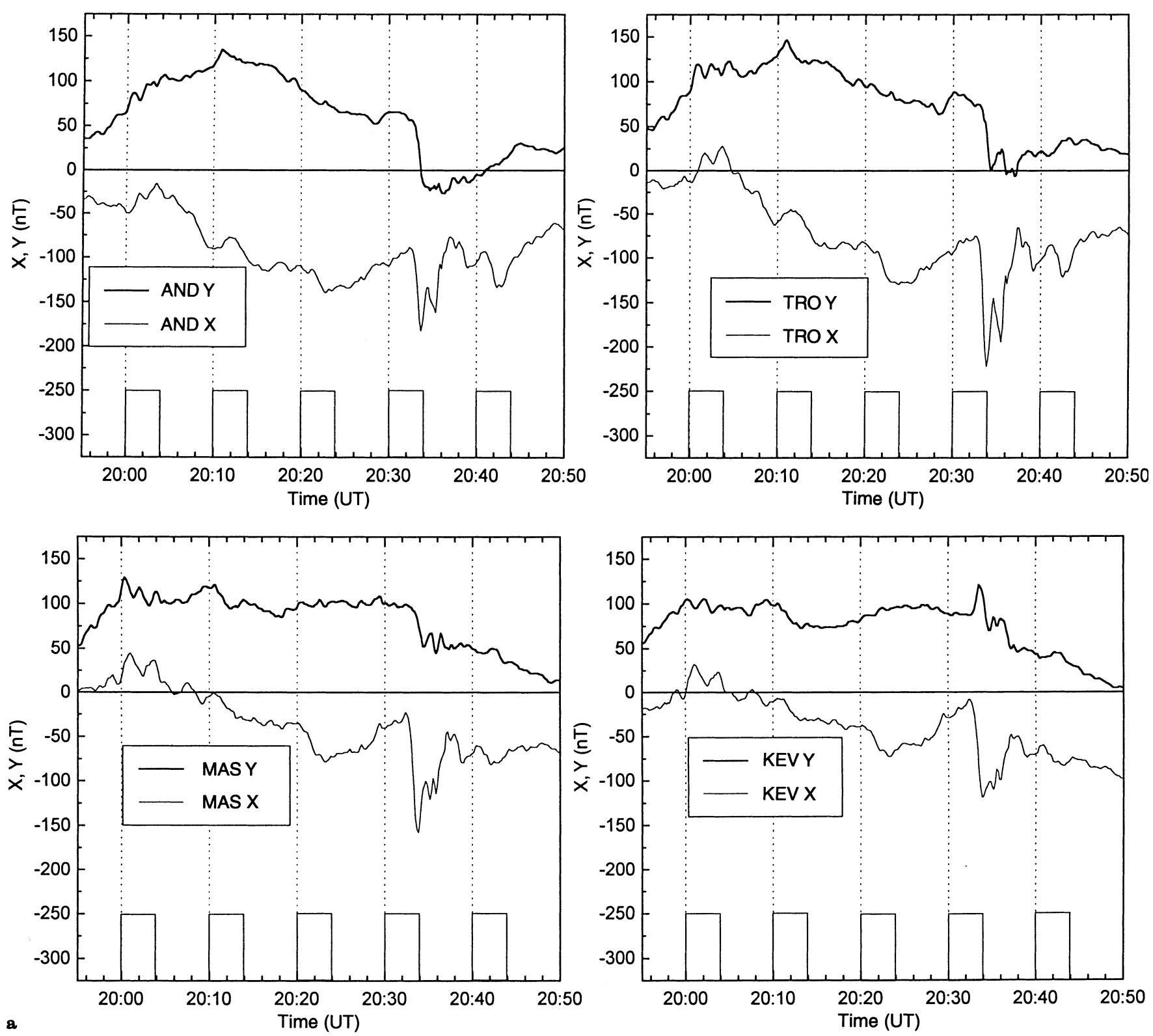

Fig. 4a, b. Perturbations of the $\mathrm{X}$ and $\mathrm{Y}$ magnetic field components from the quiet level during heating experiment on 17 February 1996 for IMAGE magnetometers, a along the latitude from AND to KEV

cycle from 20.00-20.04 UT in the area bounded by geographical latitudes from $70.5^{\circ}$ (SOR) to $68.02^{\circ}$ (MUO) and geographical longitudes from $16.03^{\circ}$ (AND) to $27.01^{\circ}$ (KEV). This area can be identified with a region covered by the upward field-aligned currents. After the Tromsø heater was turned on at 20.00 UT the abrupt increase of the oscillation amplitude in the $X$ as well as in the $Y$ component started. Note that irregular pulsations in the Pi2 range appeared only slightly in filtered magnetic data (Fig. 6) over the whole time interval analyzed. During the first heating cycle the period and phase of the ULF wave are relatively constant with latitude from SOR to the south in both magnetic components, that is the characteristic signature of a cavity resonance (McDiarmid and Allan, 1990). Maximum amplitude (peak-to-peak) from unfil-

and $\mathbf{b}$ along the longitude from BJN to OUJ (see Fig. 1b). The intervals when the Tromsø heater was turned on are marked on the time axis

tered magnetic data up to $30 \mathrm{nT}$ in $X$ and $20 \mathrm{nT}$ in $Y$ components can be seen from TRO, SOR and MAS magnetic data but they were heavily attenuated with latitude, particularly in the $X$ component. It should be noted that the ratio between $X$ and $Y$ component amplitudes is more than one, $X / Y>1$, only in a narrow latitudinal region including magnetometer stations AND, TRO, SOR, MAS and KEV that does not contrast with the field-line resonance (Yeoman et al., 1991). The resonance width was $1^{\circ}$ latitude $(110 \mathrm{~km})$. To the south, from this narrow latitudinal region, the ratio is less than one $X / Y<1$. It is of interest to estimate the relations between $Y$-component amplitudes within the width of a field-line resonance. The ratios of SOR, MAS, AND and KEV $Y$ component amplitudes to TRO $Y$ component amplitude for the first and second 

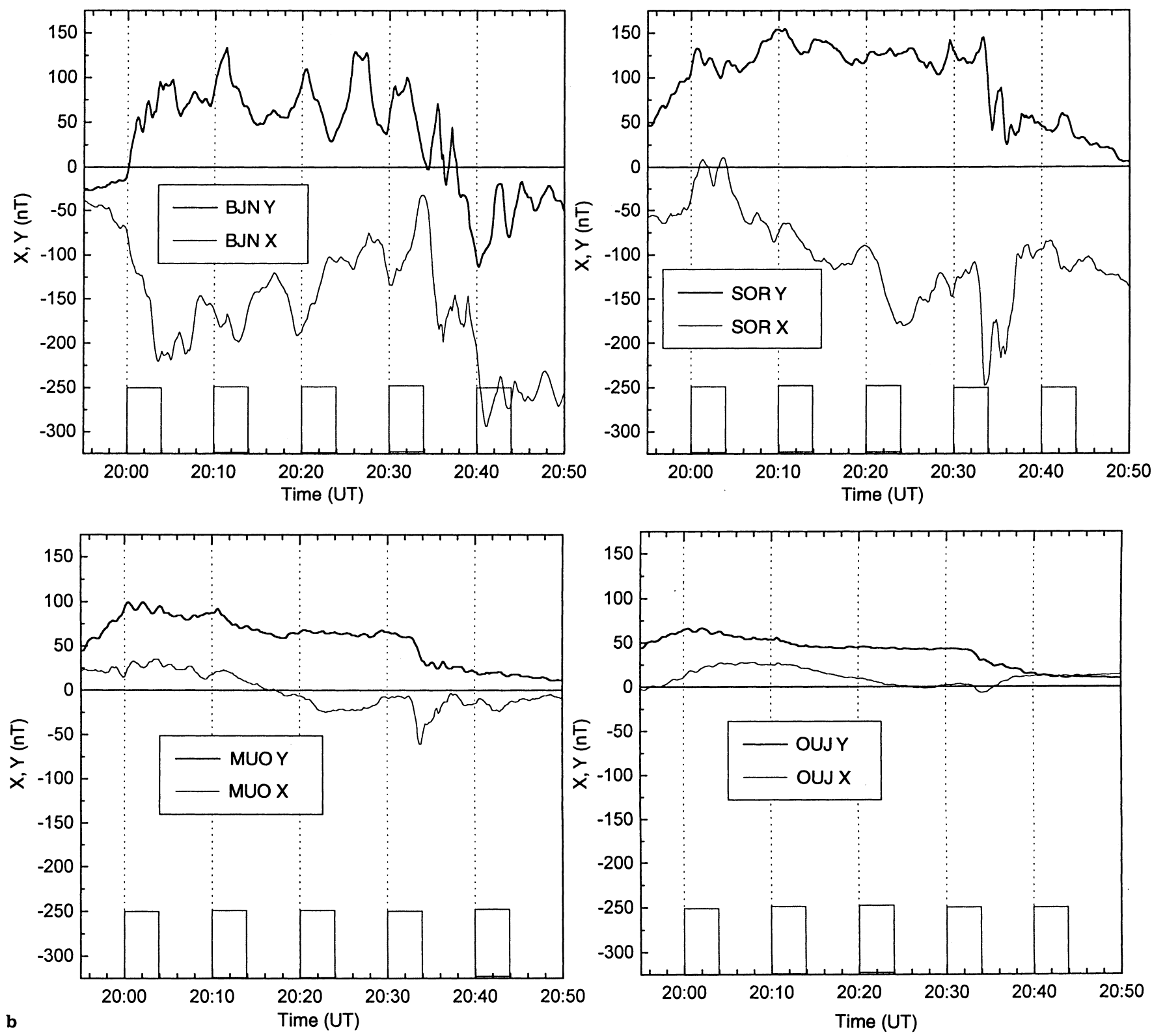

Fig. 4b.

maximums accordingly during the heater on period from 20.00-20.04 UT are the following: $Y_{\mathrm{SOR}} /$ $Y_{\mathrm{TRO}}=1.0 ; \quad 0.7, \quad Y_{\mathrm{MAS}} / Y_{\mathrm{TRO}}=1.0 ; \quad 0.8, \quad Y_{\mathrm{AND}} /$ $Y_{\mathrm{TRO}}=0.4 ; 0.4, Y_{\mathrm{KEV}} / Y_{\mathrm{TRO}}=0.6 ; 0.6$.

There is good reason to consider the polarization parameters ( $X$ - $Y$ plane) from eight IMAGE magnetometer stations for the time interval containing the first heating cycle shown in Fig. 7. One can recognize that polarizations are clockwise $(\mathrm{CW})$ to the south and anticlockwise (AW) to the north of the TRO latitude. Further examination shows the change of the polarization sense from $\mathrm{CW}$ to $\mathrm{AW}$ in the course of the first heater on period observed in the restricted longitudinal region at the TRO latitude, including TRO, MAS, SOR and KEV magnetometers. It should be noted that the nearest AND station, located to the west from TRO, did not show a change of the polarization sense. In addition, the most drastic change of polarization was first observed at TRO station and thereafter the polarization sense changes occurred at MAS, SOR and KEV magnetometer stations.

Let us consider the possible generation mechanisms of the ULF observed during substorm onset. The pulsation behavior from IMAGE magnetometer stations shows that it is not the typical signature of natural irregular Pi2 magnetic pulsations. On one hand the relation $X / Y>1$ was observed in a narrow latitudinal region around Tromsø that is not contrary to the development of the field line resonance (Yeoman et al., 1991). On the other hand the period and phase are relatively constant with latitude, as expected for a cavity resonance (McDiarmid and Allan, 1990). Moreover the 

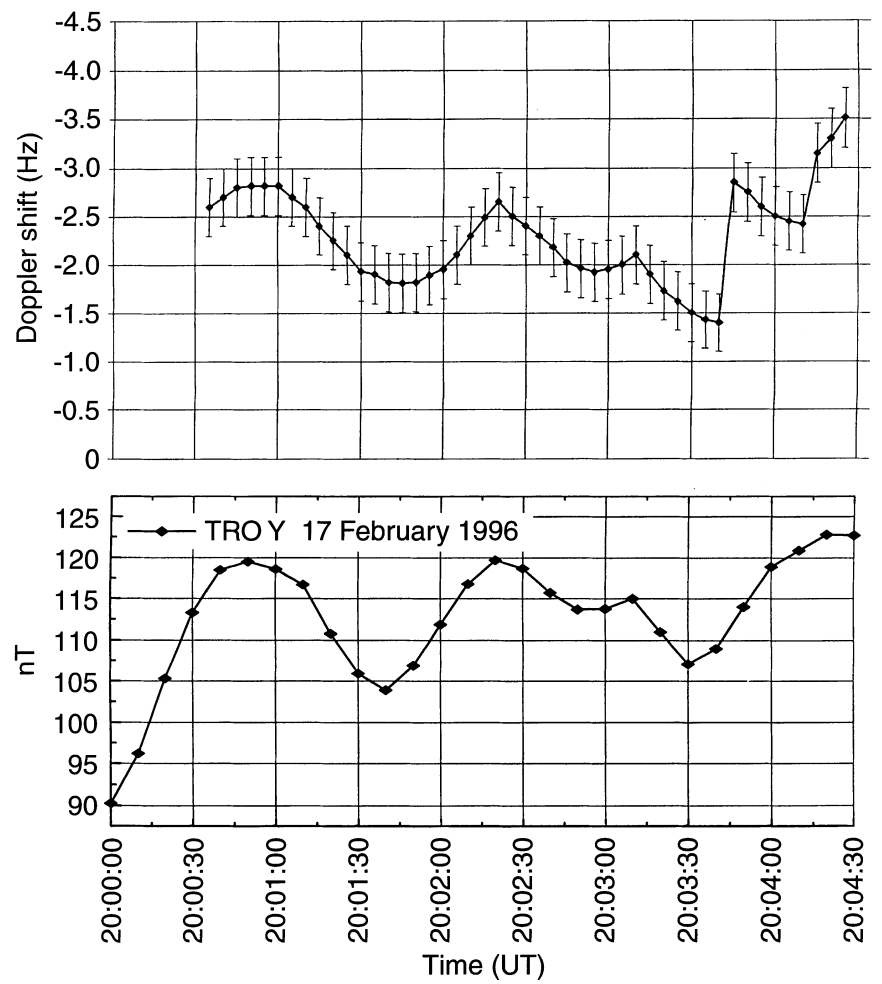

Fig. 5. The wave variations in Doppler frequency shift on the London-Tromsø-St. Petersburg path (top) and in Y component at Tromsø (bottom) during the first heating cycle (20.00-20.04 UT) on 17 February, 1996

abrupt changes of the ULF characteristics, such as amplitude and the change of the polarization sense are clearly visible during the first heater-on period. It should be noted that substorm onset and generation of the upward field-aligned currents, and, correspondingly, the establishment of the Birkeland current wedge were observed in temporal coincidence with the first heating cycle.

In our opinion the observed pulsations can result from superposition of natural and heater-induced ULF waves. The generation mechanism of the heater-induced ULF wave may be the following. The powerful HF radio wave, in the lower ionosphere, locally modifies the ionospheric conductivity. In our experiment it would be expected that the strong modification of the ionospheric conductivity resulted because the pump wave was reflected from $E_{s}$ layer. The region of the enhanced ionospheric conductivity is polarized in the background electric field, and the polarization electric field propagates into the magnetosphere along the magnetic field lines as the field of the outgoing Alfvén wave (Kan and Sun, 1985; Lysak, 1990; Borisov et al., 1996). The problem of the Alfvén wave generation over a circle-like inhomogeneity of the disturbed conductivity, where the background field-aligned current is upward, has been studied by Kozlovsky and Lyatsky (1997). From these results it may be deduced that an outgoing Alfvén wave is generated from a heater-induced inhomogeneity of the enhanced conductivity. The field-aligned current of this wave is directed as background upward current due to the total field-aligned current increases. The fieldaligned current of the Alfvén wave, reflected from the magnetosphere, would provide the downward fieldaligned current that reduces the background upward FAC. As a result the additional field-aligned currents associated with the heater-induced Alfvén wave would modulate the background upward FAC in the surge site and lead to the appearance of the magnetic and ionospheric pulsations. The period of these pulsations is determined by the Alfvén wave travel time between the ionosphere and magnetosphere. It is exactly that observed in our heating experiment for $L=6.2$ (from 100-120 s). Note that the ULF wave was observed not only at Tromsø but at other magnetometer stations located in the area of the background upward FAC as well. The effect of the background FAC modulation falls off with distance from Tromsø. It can be clearly seen from the relations between SOR, MAS, KEV and AND $Y$ component amplitudes and TRO $Y$ component amplitude (peak-to-peak) during heater-on period. We emphasize that the geophysical conditions (substorm onset, field-aligned currents, the presence of $\mathrm{E}_{\mathrm{s}}$-layer) during the heating experiment significantly control the occurrence of magnetic and ionospheric pulsations.

Thus, we conclude that the observed ULF wave in the $\mathrm{Pi} 2$ range can result from modification of natural ULF wave by the heater-induced Alfvén wave during substorm onset and initiation stage of the background upward field-aligned currents.

\subsection{Phenomena during the second activation}

From Fig. 2 it can be seen that the heater switching on at 20.30 UT leads to the appearance of field-aligned scattered HF signals as seen in the previous heating cycles. They are displaced from the direct HF signals by about $-2.5 \mathrm{~Hz}$. Then after about $60 \mathrm{~s}$ very strong emissions were observed everywhere over the analyzed spectral bandwidth. Thereafter, at 20.33 UT, the additional very intense short-lived track with an average existence of order $60 \mathrm{~s}$ appears apart from the main heating track on the sonogram. Its Doppler frequency shift is $-0.8 \mathrm{~Hz}$ from the main field-aligned track. The heater switching off, at 20.34 UT, is accompanied by the disappearance of the additional short-lived track but the emission was still supported for $1 \mathrm{~min}$. In the next heating cycle both the emission and additional shortlived track are also observed. But, in this case, the emission existed only $1 \mathrm{~min}$, and the lifetime of additional track was about $40 \mathrm{~s}$, and its $f_{d}$ is $-0.4 \mathrm{~Hz}$ from the main field-aligned track. The main field-aligned Doppler track was observed throughout the heating cycle from 20.40 to 20.44 UT.

It should be remembered that the second substorm activation started at 20.33 UT. Further examination of the IMAGE magnetometer data showed that a new westward electrojet appeared exactly above Tromsø. The reversal of the $Z$ component sign from positive (SOR) to negative (MAS) values, $\delta Z=0$, as well as the 


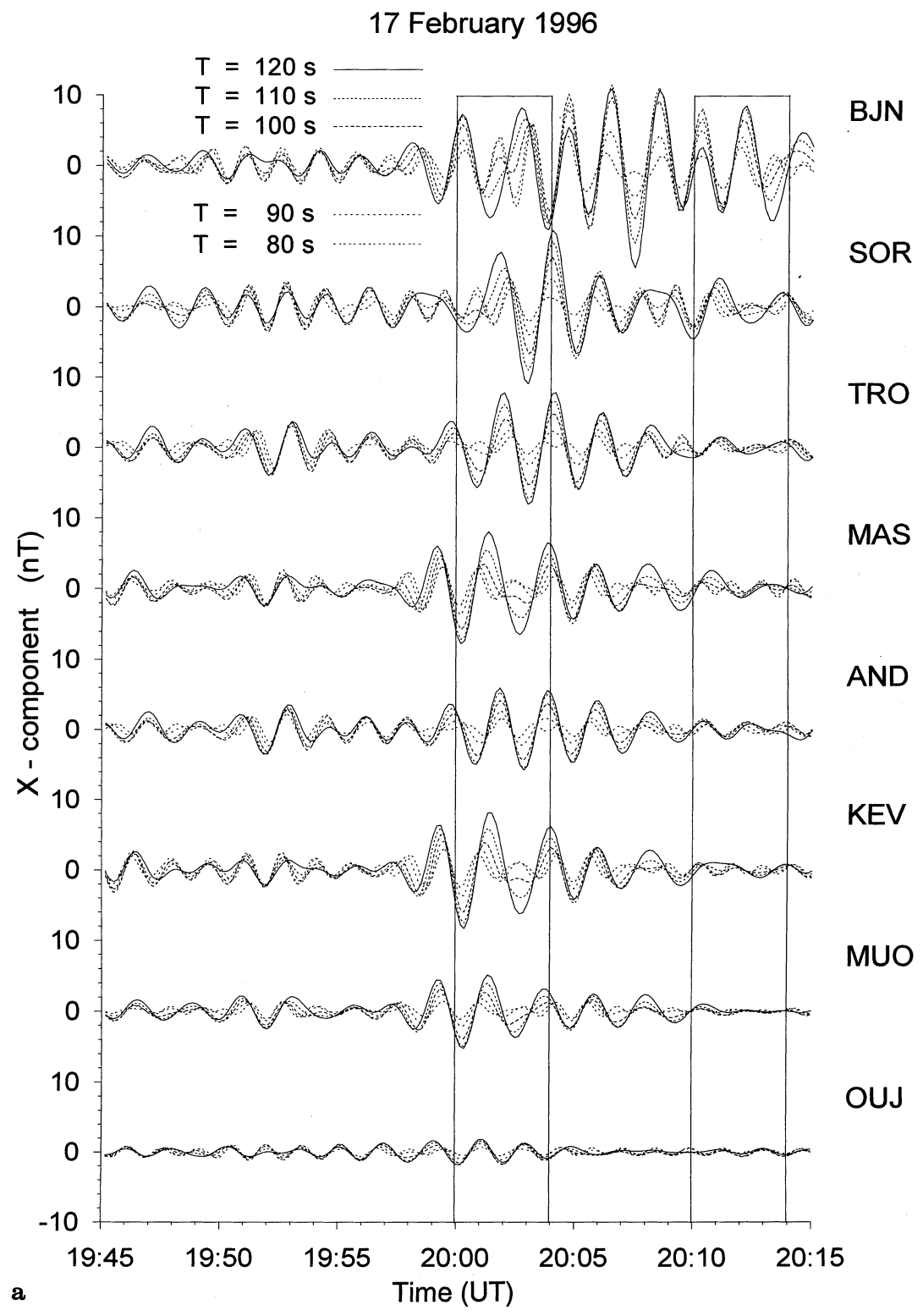

Fig. 6a, b. Magnetic field variations from eight IMAGE magnetometer stations, bandpass filtered between 120 and $80 \mathrm{~s}$ for a the $\mathrm{X}$ component and b the $\mathrm{Y}$ component maximum amplitude of the negative $X$ spike $\delta X=-150 \mathrm{nT}$ are observed in TRO magnetic data (Fig. 3a, c). Therefore, the occurrence of the additional short-lived track on the Doppler sonogram, and the onset of the second substorm activation are related to each other. In the heating cycle, from 20.40 to 20.44 UT, some intensification of the electrojet was also observed.

The heating of the auroral $\mathrm{E}_{\mathrm{s}}$ region has excited the small-scale field-aligned irregularities (striations) in the ionospheric $\mathrm{E}$ region responsible for field-aligned scattering of diagnostic HF waves. The equipment used in the experiment on 17 February was sensitive to electron density irregularities with wavelengths of $12-15 \mathrm{~m}$ across the geomagnetic field lines. The properties of these $E_{\mathrm{s}}$ region striations can be understood within the frame of the thermal resonance instability, taking place at the upper hybrid level (Vaskov and Gurevich, 1977; Inhester, 1982). Note, that E-region striations have been previously observed only with the $1 \mathrm{~m}$ STARE radar
(Noble et al., 1987) and with a mobile $3 \mathrm{~m}$ radar (Djuth et al., 1985; Noble et al., 1987).

The other unusual phenomenon observed from HF Doppler measurements at operating frequency $12095 \mathrm{kHz}$ was the generation of the well-defined stimulated electromagnetic emission (SEE) produced by the $\mathrm{E}_{\mathrm{s}}$ region heating. It is known (Thidé, 1990), that SEE results from reemission of HF induced plasma waves as electromagnetic waves due to a wave-wave interaction, as well as from their scattering by striations. If the pump frequency $f_{H}$ is not extremely close to an electron gyroharmonic, there are strong SEE signals downshifted from $f_{H}$ with a strongly pronounced maximum downshifted by the lower hybrid frequency $f_{L H}$. Such downshifted maximum, $f_{D M}=f_{H}-\mathrm{f}_{L H}$, in the SEE spectra is well known (Thidé, 1983). It is common knowledge (Leyser et al., 1989) that the lower hybrid frequency is approximately $8 \mathrm{kHz}$ in the ionosphere above Tromsø. Moreover, from SEE observa- 


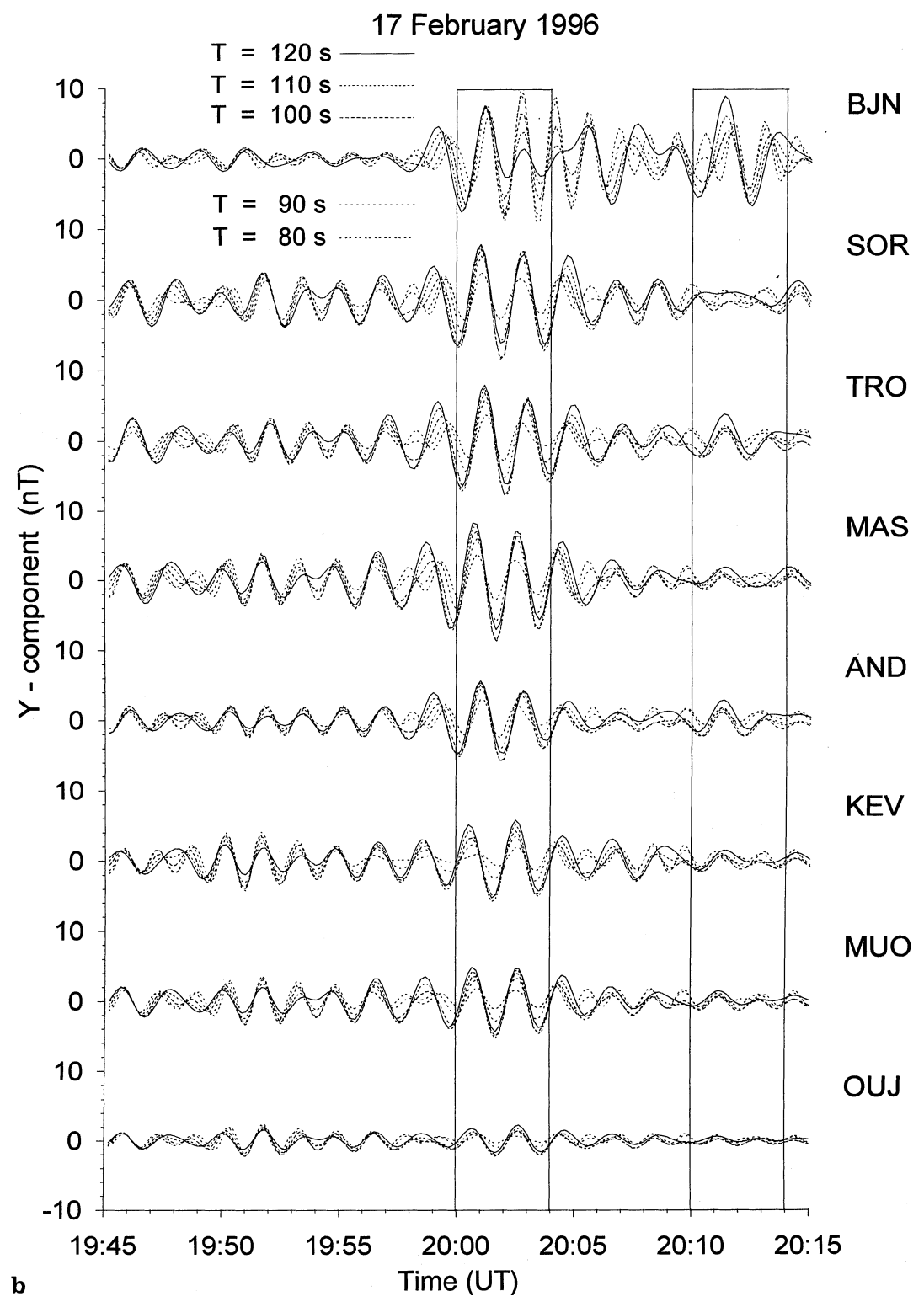

Fig. 6b.

tions around the second harmonic of the Tromsø heater frequency it was shown (Blagoveshchenskaya et al., 1998), that wide-band emissions with a pronounced maximum at the second harmonic of the downshifted maximum, $2 f_{D M}=2\left(f_{H}-\mathrm{f}_{L H}\right)$, appeared. They were registered $1200 \mathrm{~km}$ from the Tromsø heater whereas most previous SEE measurements have been made within 100 km (Leyser et al., 1989; 1990; Stubbe et al., 1984; 1990; Thidé et al., 1982; 1983). Therefore, from the result obtained it may be concluded that the SEE at the harmonics of the downshifted maximum may occur in the heating experiments. In our experiment operational frequency $(f=12095 \mathrm{~Hz})$, used for Doppler measurements of HF diagnostic signals, was equal to the third harmonic of the downshifted maximum $3 f_{D M}\left(f=3 f_{D M}, 3 f_{D M}=3\left(f_{H}-f_{L H}\right)\right.$, where $f_{H}=4040 \mathrm{kHz}, f_{H}=8 \mathrm{kHz}$ ). Because of this one can suggest that wide-band emissions on the Doppler sonogram is due to the $3 D M$ component of the SEE spectra.
The next phenomenon, closely connected with stimulated electromagnetic emissions at the frequency near the third harmonic of the downshifted maximum, was the appearance of very intense short-lived tracks with durations of 40-60 s apart from the main field-aligned tracks on the Doppler sonogram. The observed phenomenon can be qualitatively interpreted by the following. Ionospheric parameters obtained by the Tromsø dynasonde and EISCAT UHF radar show the presence of a sporadic $\mathrm{E}_{\mathrm{s}}$ layer during the second substorm activation. In the same time the auroral arc was observed from airglow data. It is a matter of general experience that these structures formed by the typical electron energies from 1 to $10 \mathrm{keV}$ (Bösinger et al., 1996). On the other side, the strong HF heaterinduced plasma waves can accelerate thermal electrons. Moreover, the generation of the strong SEE was observed. Perhaps one can concede that SEE at the frequency $3 f_{D M}$ is accompanied by the excitation of VLF waves. It is known (James et al., 1990; Kimura 
AND 19.57 - 20.07 UT 17 February 1996
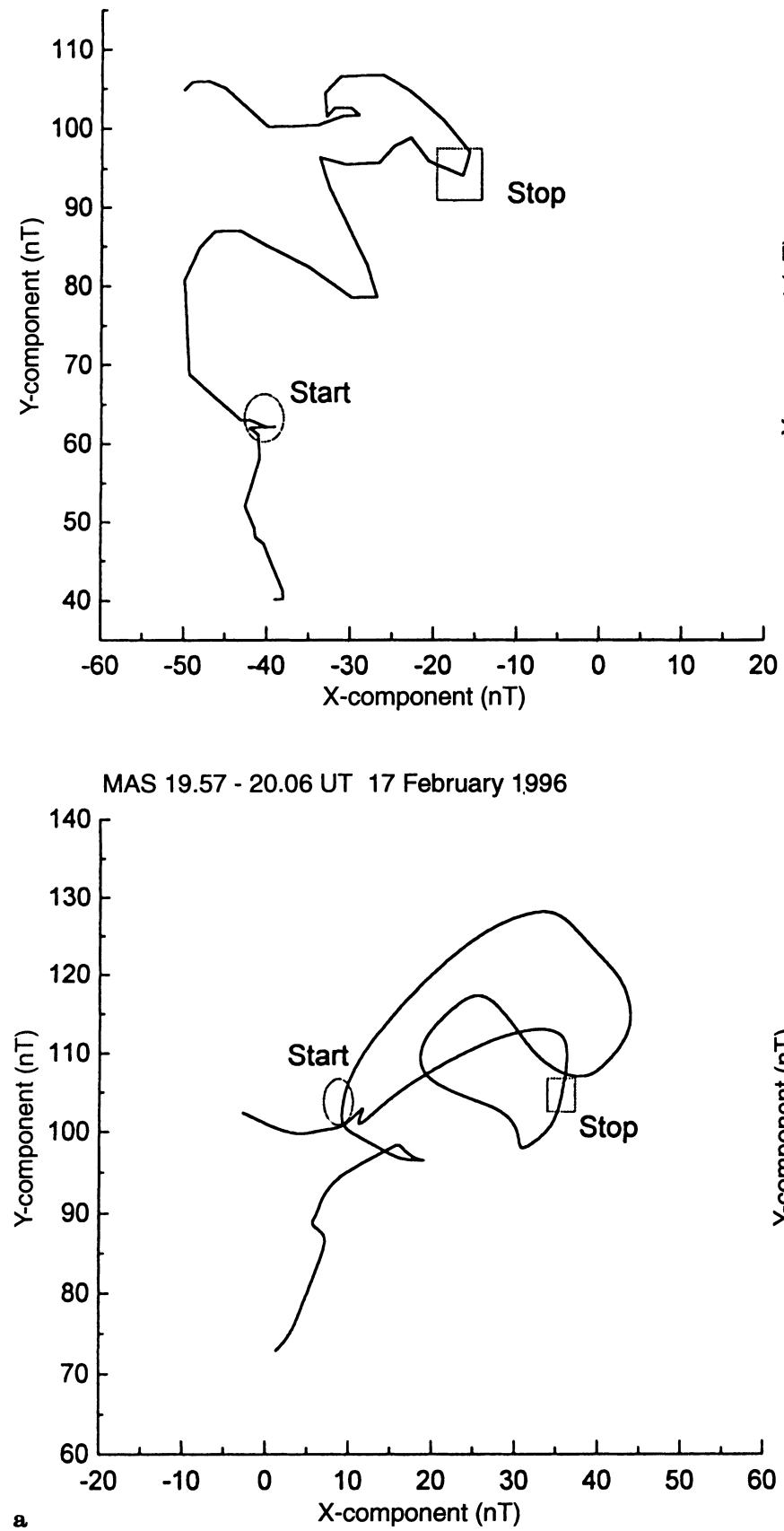

Fig. 7a, b. Hodographs presenting the time evolution of the Y-X polarization surfaces on 17 February, 1996 for the time interval from 19.57 to 20.06 UT containing the first heating cycle (from 20.00-20.04 UT) from IMAGE magnetometers, a along the latitude from AND to

et al., 1994) that VLF waves in the whistler mode are able to propagate into the upper ionosphere and magnetosphere. In this case it would be expected that the appearance of the stimulated precipitation of energetic electrons with energies between 10 and $40 \mathrm{keV}$ would occur due to a cyclotron resonant interaction of natural precipitating electrons (1$10 \mathrm{keV}$ ) with heater-induced whistler waves in the magnetosphere. It was shown by Trefall et al., (1975) that a cyclotron generation mechanism is operating in a
TRO 19.57 - 20.07 UT 17 February 1996
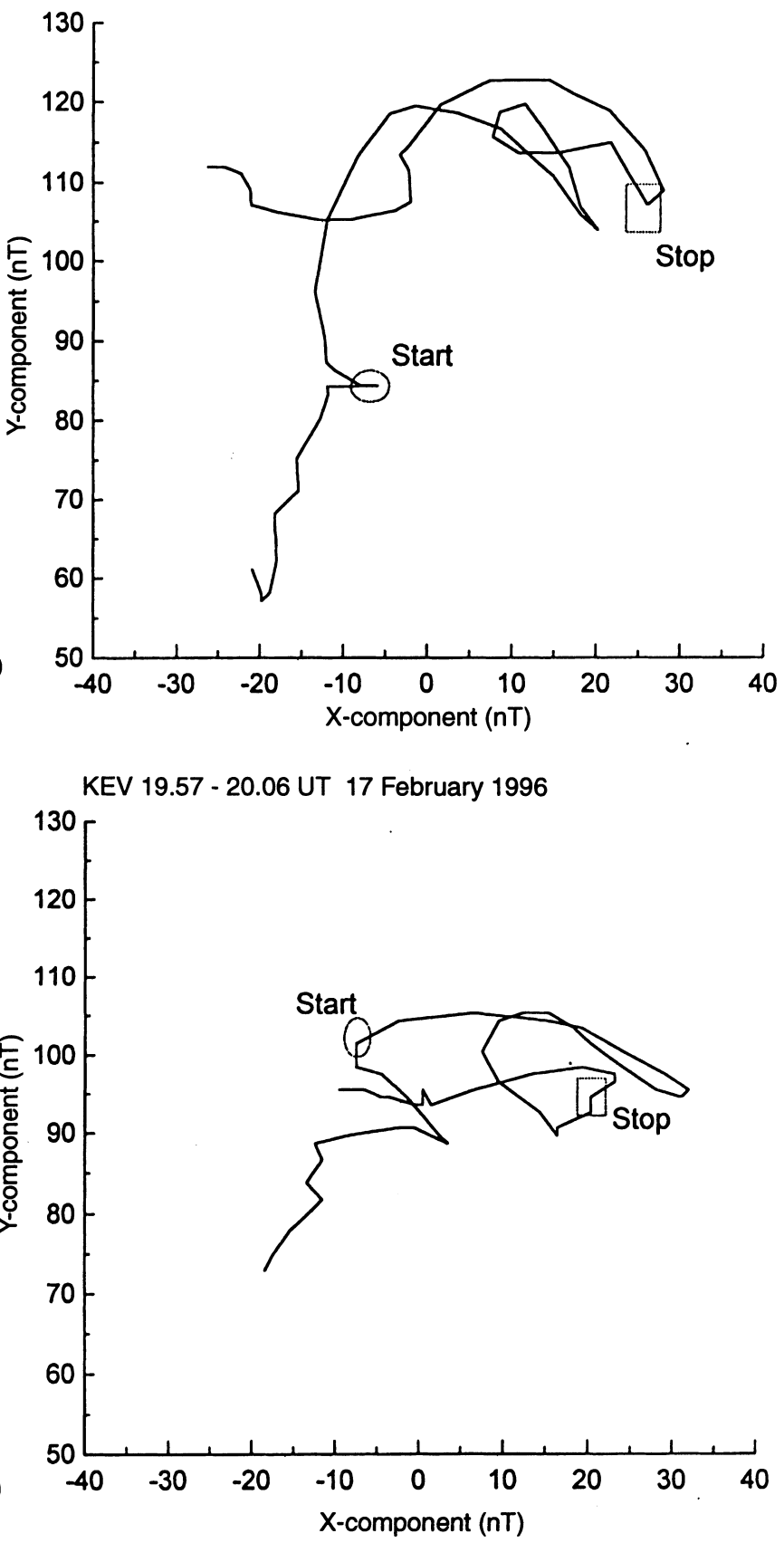

KEV and $\mathbf{b}$ along the longitude from BJN to OUJ (see Fig. 4a, b). The Tromsø heater turning on and off are marked by circles and rectangles correspondingly

narrow region of a magnetic flux tube. Therefore, two electron populations involving natural soft electrons (1$10 \mathrm{keV})$ and HF heater-induced hard electrons (10$40 \mathrm{keV}$ ) could take place during the heating experiment in the substorm maximum. There are indications that only a hard electron component took part in the short period electron precipitation as observed in a study of a pulsating auroral arc by Bösinger et al., (1996). Thus, the analysis of experimental data shows the possibility of the excitation of the stimulated electron precipitation 

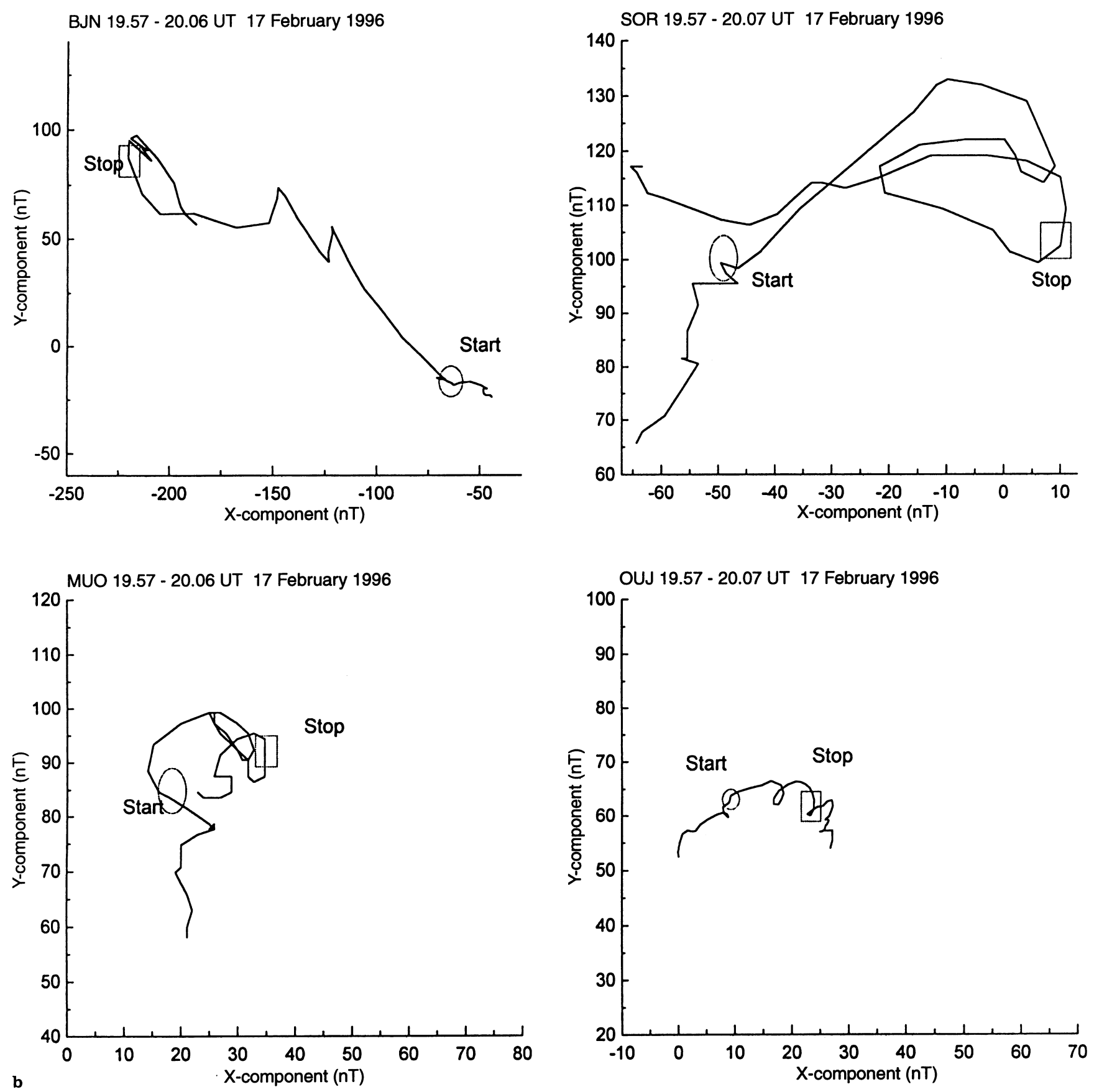

Fig. $7 \mathbf{b}$.

in the heating modification of the auroral $\mathrm{E}_{\mathrm{s}}$ region. From the result obtained it may be concluded that a new substorm activation exactly above Tromsø was intimately associated with the heater-induced precipitation of energetic electrons. The critical requirements of a similar stimulated precipitation (auroral trigger) are the presence of the field-aligned artificial irregularities in the E-region, stimulated electromagnetic emissions, possibly closely connected with heater-induced VLF waves and natural precipitation of the soft electrons.

\section{Conclusions}

We have studied phenomena initiated by the action of powerful HF radio waves at Tromsø in the nightside auroral Es region during the magnetospheric substorm on 17 February, 1996. The analysis is based on experimental data from distance-diagnostic HF tools located in St. Petersburg. Doppler measurements of HF diagnostic signals were carried out on the LondonTroms $\varnothing-$ St. Petersburg path using a fixed operating frequency of $12095 \mathrm{kHz}$. Furthermore, multi-instrument data from Tromsø dynasonde, IMAGE magnetometer network, EISCAT incoherent scatter radar, were used. 
The heating of the auroral $E_{S}$ region excited the smallscale field-aligned irregularities in the ionospheric $\mathrm{E}$ region with wavelength of the order $12-15 \mathrm{~m}$ across the geomagnetic field lines. These irregularities then act as an artificially produced target for the diagnostic HF waves on the London - Tromsø - St. Petersburg path and are responsible for field-aligned scattered diagnostic signals.

Magnetic data from IMAGE network show that the first substorm activation started at 20.00 UT and coincided exactly with the Tromsø heater turning on The substorm onset was accompanied by development of the upward field-aligned currents (FACs) at the western edge of the westward electrojet. The second substorm activation started at $20.33 \mathrm{UT}$ as a large negative spike in the $X$ component and peaked at 20.34 UT with a maximum westward electrojet exactly above Tromsø. Thereafter, a much larger substorm occurred north of Tromsø at about 20.36 UT.

The interesting peculiarity of the field-aligned scattered HF signals is the appearance of wave variations in Doppler frequency shift, $f_{d}$, with periods about 100 $120 \mathrm{~s}$ and amplitude about $0.8 \mathrm{~Hz}$ during the substorm expansion onset. These ionospheric pulsations closely correlated with magnetic pulsations in the $Y$ component of the geomagnetic field at Troms $\varnothing$, falling in the Pi2 range and with a large amplitude of the order 15 $20 \mathrm{nT}$. The relationship of the ionospheric $\left(f_{d}\right)$ and magnetic field ( $Y$ component) fluctuations corresponds to correlation between variations in the meridional, north-south component of the electric field $\left(E_{x}\right)$ and zonal, east-west component of the magnetic field $\left(B_{y}\right)$ in the artificially modified ionospheric $E_{s}$ region. Parameters of the observed ULF wave were estimated from Doppler measurement data. They are the following: the vertical displacements of the heated Es region $\mathrm{M}= \pm 600 \mathrm{~m}$ and the north-south component of electric field $E_{x}= \pm 1.3 \mathrm{mV} / \mathrm{m}$. The analysis of the magnetic field variations from the IMAGE stations shows that ULF waves occurred not only at Tromsø but in the adjacent area bounded by geographical latitudes from $70.5^{\circ}$ to $68^{\circ}$ and longitudes from $16^{\circ}$ to $27^{\circ}$. This area can be identified with region covered by the upward field-aligned currents. Moreover it was found the change of the polarization sense $(X-\mathrm{Y}$ plane) from clockwise to anticlockwise in the course of the first heater-on period observed in a narrow latitudinal region around Tromsø $(110 \mathrm{~km})$. It does not contrary to the development of the field line resonance. We conclude that the observed ULF wave in the $\mathrm{Pi} 2$ range can be result from strong modification of natural ULF wave by the heater-induced Alfvén wave. It may be deduced that Alfvén wave is generated from a heater-induced inhomogeneity of the enhanced conductivity during substorm onset and initiation stage of the background upward field-aligned currents (FACs). As a result the additional field-aligned currents of this Alfvén wave would modulate the background upward FAC in the surge site. The effect of the background FAC modulation falls off with distance from Tromsø.
During substorm expansion we found the welldefined stimulated electromagnetic emissions (SEE) at the third harmonic of the downshifted maximum frequency $\left(3 f_{D M}\right)$. The next phenomenon, closely connected with this SEE, was the appearance of very intense short-lived tracks (40-60 s) on Doppler sonogram apart of the main field-aligned tracks caused by the artificial field-aligned small-scale irregularities (striations) in the $\mathrm{E}_{\mathrm{S}}$ region during heater-on periods. It was suggested, that the SEE at the frequency of $3 f_{D M}$ is accompanied by the excitation of VLF waves, which in whistler mode are able to penetrate into the magnetosphere. Then, a cyclotron resonant interaction of natural precipitating electrons (1-10 keV) with heater-induced whistler waves in the magnetosphere leads to stimulated precipitation of more hard electrons with energies $10-40 \mathrm{keV}$, responsible for the appearance of additional short-lived tracks on Doppler sonogram. We conclude that the second substorm activation exactly above Tromsø was intimately associated with the heater-induced precipitation of energetic electrons.

Results of the Tromsø heating experiment in the nightside auroral $E_{S}$ region clearly show the evidence on the modification of the ionosphere-magnetosphere coupling during magnetospheric substorm, produced by powerful HF radio waves. The distinctive behavior of the auroral ionosphere as well as field-aligned currents, precipitating particles, ionospheric convection, and substorm current wedge system significantly control the type and properties of observed phenomena. It must be underscored that the heating of the auroral ionosphere, essentially during magnetospheric substorms, leads to the generation of the new phenomena including trigger effects not encountered in the dayside, undisturbed ionosphere.

Acknowledgements. We would like to thank the Director and Staff of the EISCAT Scientific Association. EISCAT is an International Association supported by Finland (SA), France (CNRS), the Federal Republic of Germany (MPG), Japan (NIPR), Norway (NFR), Sweden (NFR) and the United Kingdom (PPARC). This work was supported by grants from the Norwegian Research Council and the Ministry of foreign affairs of Norway (The Barents Programme). Russian authors are also grateful to Russian Foundation of Fundamental Researches, grant 97-05-65443. Ari Viljanen of the Finnish Meteorological Institute (FMI) kindly supplied the IMAGE magnetometer data. The authors thank M. Kosch for airglow data.

Topical Editor D. Alcaydé thanks A. Stocker and another referee for their help in evaluating this paper.

\section{References}

Blagoveshchenskaya, N. F., V. A. Kornienko, M. T. Rietveld, B. Thidé, and A. Brekke, Stimulated emissions around second harmonic of Tromsø heater frequency observed by longdistance diagnostic HF tools, Geophys. Res. Lett., 25, 873-878 1998.

Bösinger, T., K. Kaila, R. Rasinkangas, P. Pollari, J. Kangas, V.Trakhtengerts, A. Demekhov, and T. Turunen, An EISCAT study of a pulsating auroral arc: simultaneous ionospheric electron density, auroral luminosity and magnetic field pulsations, J. Atmos. Terr. Phys., 58, 23-35, 1996. 
Borisov N., A. Gurevich, K. Papandopoulus, and C. L. Chang, Controlled generation of coherent low frequency ULF/ELF/ VLF, Radio Sci., 31, 859-867, 1996.

Djuth, F. T., R. J. Jost, S. T. Noble W. E. Gordon, P. Stubbe, H. Kopka, E. Nielsen R. Bostrem, H. Derblom, A. Hedberg, and B. Thidé, Observation of $\mathrm{E}$ region irregularities generated at auroral latitudes by a high power radio wave, J. Geophys. Res., 90, 12293-12306, 1985.

Inhester, B., Thermal modulation of the plasma density in ionospheric heating experiments, J. Atmos. Terr. Phys., 44, 1049-1059, 1982.

James, H. G., U. S. Inan, and M. T. Rietveld, Observations on the DE-1 spacecraft of ELF/VLF waves generated by an ionospheric heater, J. Geophys. Res., 95, 12187-12195, 1990.

Kamide, Y., and W. Baumjohann, Magnetosphere-ionosphere coupling, 178 pp., Springer-Verlag, New York Berlin Heidelberg, 1993.

Kan, J. R., and W. Sun, Simulation of the westward traveling surge and Pi2 pulsations during substorms, J. Geophys. Res., 90, 10 911-10 922, 1985.

Kimura, I., P. Stubbe, M. T. Rietveld, R. Barr, K. Ishida, Y. Kasahara, S. Yagitani, and I. Nagano, Collaborative experiments by Akebono satellite, Tromsø ionospheric heater, and EISCAT, Radio Sci., 29, 23-37, 1994.

Leyser, T. B., B. Thidé, H. Derblom A. Hedberg, B. Lundborg, P. Stubbe, and H. Kopka, Stimulated electromagnetic emission near electron cyclotron harmonics in the ionosphere, Phys. Rev. Lett., 63, 1145-1147, 1989.

Leyser,T. B., B. Thidé, H. Derblom, A. Hedberg, B. Lundborg, P. Stubbe, and H. Kopka, Dependence of stimulated electromagnetic emission on the ionosphere and pump wave, J. Geophys. Res., 95, 17 223-17 244, 1990.

Lühr, H., The IMAGE magnetometer network, Step Int. Newsl., 4, (10), 4-6, 1994.

Lysak, R. L., Electrodinamic coupling of the magnetosphere and ionosphere, Space Sci.Rev., 52, 33-37, 1990.

McDiarmid, D. R., and W. Allan, Simulation and analysis of auroral radar signatures generated by a magnetospheric cavity mode, J. Geophys. Res., 95, 20911-20922, 1990.

Noble, S. T., F. T. Djuth, R. J. Jost, W. E. Gordon, A. Hedberg, B. Thidé, H. Derblom, R. Bostrem, E. Nielson, P. Stubbe, and H. Kopka, Multiple frequency radar observations if high-latitude E region irregularities in the HF modified ionosphere, J. Geophys. Res., 92, 13613-13627, 1987.

Rietveld, M. T., H. Kohl, H. Kopka, and P. Stubbe, Introduction to ionospheric heating at Tromsø-1. Experimental overview, J. Atmos. Terr. Phys., 55, 577-599, 1993.
Robinson, T. R., F. Honary, A. J. Stocker, T. B. Jones, and P. Stubbe, First EISCAT observations of the modification of Fregion electron temperatures during RF heating at harmonics of electron gyrofrequency, J. Atmos. Terr. Phys., 58, 385-395, 1996.

Rostoker, G., Phenomenology and physics of magnetospheric substorms, J. Geophys. Res., 101, 12955-12973, 1996.

Sedgemore, K. J. F., J. W. Wright, P. J. S. Williams, G. O. L. Jones and M. T. Rietveld, Plasma drift estimates from the dynasonde: comparison with EISCAT measurements, Ann. Geophysicae, 16, 1998, this issue.

Stocker, A. J., F. Honary, T. R. Robinson T. B. Jones, and P. Stubbe, Anomalous absorption during artificial modification at harmonics of the electron gyrofrequency, J. Geophys. Res., 98, 13627-13634, 1993.

Stubbe, P., Review of ionospheric modification experiments at Tromsø, J. Atmos. Terr. Phys., 58, 349-368, 1996.

Stubbe, P. and H. Kopka, Stimulated electromagnetic emission in a magnetised plasma: a new symmetric spectral feature, Phys. Rev. Lett., 65, 183-186, 1990.

Stubbe, P., H. Kopka, B. Thidé, and H. Derblom, Stimulated electromagnetic emission: a new technique to study the parametric decay instability in the ionosphere, J. Geophys. Res., 89 , 7532-7536, 1984.

Thidé, B., Stimulated scattering of large amplitude waves in the ionosphere: experimental results, Phys. Scripta, T30. 170-180, 1990.

Thidé, B., H. Kopka, and P. Stubbe, Observations of stimulated scattering of a strong high-frequency radio wave in the ionosphere, Phys. Rev. Lett., 49, 1561-1564, 1982.

Thidé, B., H. Derblom, A. Hedberg, H. Kopka, and P. Stubbe, Observations of stimulated electromagnetic emissions in ionospheric heating experiments, Radio Sci., 18, 851-859, 1983.

Trefall, H., S. Ullaland, S. Singstad, I. Pytte, K. Bronstrad, J. Bjordal, R. H. Karas, R. R. Brown, and J. Muench, Morphology and fine time structure of an early morning electron precipitation event, J. Atmos. Terr. Phys., 37, 83-105, 1975.

Vaskov, V. V., and A. V. Gurevich, Resonance instability of smallscale plasma perturbations, Zh. Eksp. Teor. Fiz., 73, 923-936, 1977 (transl. in Soviet. Phys. Jetp, 46, 487-494, 1978).

Yeoman, T. K., M. Lester, D. K. Milling, and D. Orr, Polarization, propagation and MHD wave modes of $\mathrm{Pi} 2$ pulsations: SABRE/ SAMNET results, Planet. Space Sci., 39, 983-998, 1991.

Yeoman, T. K., D. M. Wright, T. R. Robinson, J. A. Davies and M. T. Rietveld, High spatial and temporal resolution observations of an impulse-driven field line resonance in radar backscatter artificially generated with the Tromsø heater, Ann. Geophysicae, 15, 634-644, 1997. 